\title{
CONSTRUCCIÓ I VALIDACIÓ D'INSTRUMENTS PER AVALUAR COMPETÈNCIES GENÈRIQUES, EN EDUCACIÓ SUPERIOR
} CONSTRUCCIÓN Y VALIDACIÓN DE INSTRUMENTOS PARA EVALUAR COMPETENCIAS GENÉRICAS, EN EDUCACIÓN SUPERIOR

CONSTRUCTION AND VALIDATION OF INSTRUMENTS

TO ASSESS GENERIC COMPETENCES, IN HIGHER EDUCATION

\section{Gracia Navarro Saldaña*, María-Gracia González Navarro**, Cristhian Pérez Villalobos ${ }^{* * *}$, Marcela Varas Contreras ${ }^{* * * *}$}

DOI: 10.7203/anuari.psicologia.17.2.113

\begin{abstract}
Resum
Es presenta una alternativa d'avaluació per a les competències genèriques que es desenvolupen en educació superior, considerant la seua característica de multidimensionalitat. Es construeixen instruments per a avaluar la dimensió cognitiva, afectiva i conductual del pensament crític, comunicació, emprenedoria i treball en equip i, responsabilitat social. S'analitza la seua validesa de constructe per mitjà d'anàlisi factorial exploratòria i confiabilitat, per mitjà del càlcul del coeficient de consistència interna -alfa de Cronbachd'una mostra de 493 estudiants de primer any de carrera durant l'any 2015.
\end{abstract}

* Directora del Programa d'estudis sobre la responsabilitat social de la Universidad de Concepción (UdeC). Correspondència: Víctor Lamas, 1290, Concepción (Chile). <gnavarro@udec.cl>.

** Assessora en Competències Genèriques (UdeC).<mgonzalez@udec.cl>.

**** Acadèmic Facultat de Medicina (UdeC). <cperezv@udec.cl>.

***** Acadèmica Facultat d'Enginyeria (UdeC) <mvaras@udec.cl>. 
Els resultats suggereixen que es disposa d'instruments confiables i vàlids, per tant, adients per a l'avaluació de la dimensió cognitiva, conductual i afectiva de les competències genèriques.

Paraules clau: competències genèriques, mesurament, multidimensionalitat, rúbrica, anàlisi factorial exploratòria.

\title{
Resumen
}

Se presenta una alternativa de evaluación para las competencias genéricas que se desarrolan en educación superior, considerando su característica de multidimensionalidad. Se construyen instrumentos para evaluar la dimensión cognitiva, afectiva y conductual del pensamiento crítico, comunicacióm, iniciativa emprendedora y trabajo en equipo y, responsabilidad social. Se analiza su validez de constructo, por medio del anàáisis factorial exploratorio y confiabilidad, a través del cálculo del coeficiente de consistencia interna-alfa de Cronbach-de una muestra de 493 estudiants de primer año de carrera, durant 2015.

Los resultados sugieren que se dispone de instrumentos confiables y válidos, por tanto, adecuados para la evaluación de la dimensión cognitiva, conductual y afectiva de las competencies genéricas.

Palabras clave: competencias genéricas, medición, multidimensionalidad, rúbrica, anàlisis factorial exploratorio.

\begin{abstract}
An alternative to assess generic competencies in higher education students is presented, given its multidimensional feature, is presented. Instruments are built to assess cognitive, affective and behavioral dimension of critical thinking, communication, entrepreneurship and interdisciplinary teamwork and social responsibility. Its reliability is analyzed using Exploratory Factor Analysis and its internal consistency by calculating Cronbach's alpha in a sample of 493 freshers during 2015.

Results suggest that instruments constructed possess adequate reliability and internal consistency, therefore, they are suitable to assess cognitive, behavioral and affective dimension of generic competencies.
\end{abstract}

Key words: generic competencies, assessment, multidimensionality, rubric, Exploratory factor analysis. 


\section{Introducció}

La creació de l'Espai Europeu d'Educació Superior (EEES), va posar èmfasi en l'educació centrada en l'aprenentatge dels estudiants i per tant, la formació de competències observables en l'acompliment dels futurs professionals -Community research and development information service, 2006-. Dins d'aquestes, es va posar especial atenció en les competències genèriques (CG), les quals es consideren com els aspectes no disciplinars que un professional, independent de la seua àrea d'estudi hauria de desenvolupar (González i Wagenaar, 2006) per lliurar una resposta més completa a les demandes socials actuals (Brewerton, 2004; Mashitoh, 2012; Qualifications and Curriculum Authority, 2004). Des de llavors, institucions d'educació superior han implementat models educatius per a formar als seus estudiants en aquests aspectes. Entre aquestes, la Universitat de Concepción de Chile (UdeC), ha proposat un model educatiu de formació transversal en quatre competències genèriques, les quals es descriuen i defineixen en la taula 1 .

TAULA 1

Competències genèriques del Model educatiu UdeC

\begin{tabular}{|l|l|}
\hline COMPETÈNCIA GENÈRICA & \multicolumn{1}{|c|}{ DEFINICIÓ DEL MODEL UDEC } \\
\hline Pensament crític & $\begin{array}{l}\text { Pensament d'ordre superior autònom i actiu que } \\
\text { s'orienta a l'anàlisi sistemàtica de les necessitats del } \\
\text { medi social i ambiental. }\end{array}$ \\
\hline Comunicació & $\begin{array}{l}\text { Capacitat d'expressar amb claredat, coherència i pre- } \\
\text { cisió les idees, coneixements i sentiments, adequant-se } \\
\text { a diferents contextos d'acord amb les característiques } \\
\text { de l'audiència a la qual es dirigeix. }\end{array}$ \\
\hline $\begin{array}{l}\text { Emprenedoria i treball en equip } \\
\text { interdisciplinari }\end{array}$ & $\begin{array}{l}\text { Capacitat de treballar en equip interdisciplinari per } \\
\text { emprendre i innovar en qualsevol àmbit d'activitat. }\end{array}$ \\
\hline Responsabilitat social & $\begin{array}{l}\text { Capacitat, intenció, i obligació de respondre davant la } \\
\text { societat, per accions o omissions professionals que } \\
\text { impacten el bé comú. }\end{array}$ \\
\hline
\end{tabular}

Taula elaborada a partir de Navarro, Vaccarezza, González i Catalán (2015).

El model proposat considera la multidimensionalitat de les competències (Nordenflycht, 2011), i fa èmfasi en la formació de cadascuna de les dimensions - cognitiva, afectiva i conductual-, d'acord amb l'etapa de la carrera en la qual es troben els estudiants. Així, durant els dos primers anys de carrera corresponents al cicle bàsic, es fa èmfasi en el desenvolupament de la dimensió cogni- 
tiva. En els dos anys següents, corresponents al cicle de llicenciatura, èmfasi en la formació de la dimensió afectiva i, en el cicle professional corresponent al 5è any de carrera d'ara endavant, es fa èmfasi en la dimensió conductual de les competències genèriques (Navarro, Vaccarezza, González i Catalán, 2015).

La implementació d'aquest model va portar a la llum un problema ja detectat en la literatura especialitzada: l'absència d'instruments vàlids per a avaluar les competències genèriques considerant la seua multidimensionalitat, i per tant, que responguen a la necessitat de prendre decisions pedagògiques per a la formació integral dels estudiants. Per això, la Universitat de Concepción va emprendre la cerca d'instruments que permeteren donar resposta a les seues necessitats, i va generar un sistema d'avaluació que lliura informació sobre les quatre competències genèriques que forma i en les tres dimensions.

Si bé cada competència genèrica implica un acompliment complex en el qual s'articulen i integren les dimensions cognitiva, afectiva i conductual, al moment de mesurar-les, per enfortir el seu desenvolupament mitjançant un model educatiu específic per a això, es proposa utilitzar, amb validacióprèvia, instruments que mesuren l'acompliment -dimensió conductual- i després la dimensió afectiva i cognitiva de manera independent. Això, perquè la formació longitudinal que proposa el model educatiu requereix identificar avanços que s'espera aconseguir en la dimensió cognitiva, després de dos anys de formació, i en la dimensió afectiva després de quatre anys de formació i, d'altra banda, el mesurament inicial, en primer any de carrera, pot llançar informació rellevant per a implementar accions educatives amb major èmfasi en les dimensions menys desenvolupades.

En aquest estudi, es mostra l'anàlisi psicomètric realitzat als tres instruments creats, els queresponen a cadascuna de les dimensions de les competències. L'anàlisi es duu a terme a partir de l'avaluació feta a 493 estudiants de primer any de diferents carreres, cosa quepermet disposard'una diversitat representativa de la població d'estudiants que ingressen en la universitat i d'un nombre de subjectes adequat per a realitzar les anàlisis estadístiques pertinents.

\section{Consideracions en la construcció d'instruments d'avaluació per a mesurar competències genèriques}

L'educació per competències va comportar una discussió sobreles estratègies d'avaluació, d'una banda, quant a l'abordatge del procés d'avaluació en si mateix, i d'una altra, l'elecció d'instrumentsa través delsquals avaluar. En relació a l'enfocament d'abordatge, sembla que l'avaluació autèntica és la forma més propícia per a avaluar i formar en competències genèriques (Sabirón i Arraiz, 2013). Aquesta metodologia persegueix que l'avaluació es transforme en una oportunitat d'aprenentatge per als esatudiants, $i$ implicaque en ser ava- 
luats, exercisquen les competències que han après durant la seua formació i que haurien de correspondre a les mateixes que utilitzaran en l'ambient laboral (Fernández, 2010; Raymond, Homer, Smith, i Gray, 2013).

A més, aquesta metodologiaté efectes beneficiosos per a l'aprenentatge de l'estudiant, com el desenvolupament d'habilitats cognitives d'alt nivell, aprenentatge significatiu i facilitació de la transferència (Boud, 1995, en Raymond i al., 2013; Navarro i González, 2010). Per tant, quan dissenyem instruments que avaluen la dimensió cognitiva -el que els estudiants coneixen-, afectiva-el valor que els lliuren i ladisposició a treballar per desenvolupar-les- i conductual -el que els estudiants fan- de les competències genèriques, és imprescindible que els instruments oferisquen oportunitats perquè els estudiants despleguen els aprenentatges obtinguts en cadascuna de les dimensions.

D'altra banda, la construcció d'instruments a través delsquals avaluar implica una sèrie de consideracions, dins de les quals, Chapman i O'Neill (2010) n'esmenten les següents: en primer lloc, l'alt nivell d'abstracció en la definició dels conceptes d'aquest tipus, cosa que genera dificultat a l'hora de determinar la forma en què les C.G. poden ser observades i, per tant, la creació d'indicadors concrets que puguen ser mesurats en l'avaluació. En segon lloc, la superposició que tenen les C.G. entre si, que afecten el perfil general de l'eixida dels estudis, és a dir, l'assoliment o fracàs en el desenvolupament d'una competència podria afectar l'acompliment en una altra. Finalment, una tercera dificultat, és que en l'acompliment d'algunes competències, els trets personals són centrals, i això implica un risc en el mesurament, ja que depenent de com es definisquen, podria ocórrer que siguen els trets personals tot el que es mesure en aquestes.

La literatura no estableix clarament enfocaments o instruments per a mesurar competències genèriques (Chapman i O'Neill, 2010). No obstant això, tenint en compte el principi d'avaluació autèntica abans esmentat i les consideracions que s'han realitzat sobre aquest tema,en aquest cas es va decidir generar un sistema d'avaluació que considerara la conceptualització de cada competència genèrica d'acord amb el model educatiu de la institució, que operacionalizara l'esperat en els perfils d'eixida dels estudisi que sense importar si els aspectes desenvolupats eren part dels trets personals dels estudiants o si eren formats durant la carrera, permetera mesurar-los en el seu acompliment. D'altra banda, que donaren resposta a les necessitats pedagògiques de la institució i que aportaren al camp de coneixement en aquesta àrea. Finalment, una consideració sempre present en el moment d'escollir un instrument, és el grau de confiabilitat i validesa de les dades que lliura. La qual cosa implica l'anàlisi psicomètrica dels instruments i moltes vegades, l'adequació d'aquests a la realitat en la qual seran utilitzats. Com es va esmentar anteriorment, en aquest estudi es mostra l'anàlisi psicomètrica dels instruments creats, la qual va quedar composta per dues rúbriques analítiques i una escala de valoració. 


\section{Rúbriques i escales de valoració en el mesurament de competències genèriques}

Les rúbriques corresponen a instruments que estableixen criteris a avaluar i nivells escalars d'acompliment que especifiquen l'estàndard per a cadascun (Ciudad i Valverde, 2014; Irles, Ortells, De la Calle i De la Sen Fernández, 2011; Jonsson i Svingby, 2007), la qual cosa en conjunt permet determinar la qualitat de l'execució dels estudiants. Les rúbriques analítiques, com les construïdes en aquest estudi, són aquelles en les quals s'emet un judici per cada criteri establert en la rúbrica (Jonsson i Svingby, 2007). Aquests instruments han mostrat diferents avantatges en un procés educatiu centrat en l'aprenentatge, entre aquests, promoure l'autonomia dels estudiants per mitjà de la claredat i transparència dels nivells d'acompliment, així ells poden conèixer, monitorar i regular el seu propi aprenentatge (Irles i al., 2011) i el fet que aquells nivells d'acompliment serveixen com a guia de treball per als professors, ja queportenllum sobre el que els seus estudiants haurien d'aconseguir, i possibiliten oportunitats de millora en la presa de decisions en relació a les estratègies d'ensenyament (Ciudad i Valverde, 2014).

Una de les febleses que implica l'avaluació per mitjà de rúbriques és la dificultat d'asseverar que les observacions realitzades a partir de l'acompliment són creïbles i confiables, i ésfins i tot més important tenir certesa d'aquesta informació quan els resultats de l'avaluació tenen conseqüències importants per als estudiants (Jonsson i Svingby, 2007). Per resoldre això, la difusió de rúbriques en la literatura especialitzada, s'acompanya freqüentment de l'anàlisi de confiabilitat i validesa dels instruments, valors amb una acceptació que varia segons el propòsit de l'instrument (Bojórquez, López, Hernández i Jiménez, 2013; Jonsson i Svingby, 2007). D'altra banda, una dificultat observada i expressada durant aquesta avaluació per aquells que la van aplicar, és que implica una demanda alta de temps i una capacitació prèvia al seu ús, cosa que es va intentar solucionar per mitjà d'un taller de preparació i per la contractació d'avaluadors externs.

En relació a les escales de valoració, les escales tipus Likert han estat altament recomanades per al mesurament d'actituds pel seu nivellalt de confiabilitat i validesa, per la seua fàcil administració i avaluació, i perquè permeten l'operacionalització de constructes abstractes per mitjà de les asseveracions en els ítems i l'autoinforme dels que responen (Neligia, 2001). D'altra banda, per $\mathrm{a}$ aspectes pedagògics, tot $\mathrm{i}$ que a diferència de la rúbrica permet una ràpida administració, poden deixar de costat informació important a escala qualitativa. No obstant això, atesa l'opció de conèixer l'acompliment d'un gran nombre d'estudiants, es va optar per un instrument d'aquest tipus. 


\section{Proposta del sistema d'avaluació}

El disseny del sistema d'avaluació va considerar els principis d'avaluació autèntica, quant al lliurament d'oportunitats per a exercir els aprenentatges obtinguts pels estudiants i els avantatges i febleses dels instruments exposats anteriorment. Així, en un mateix context es van avaluar les tres dimensions de les quatre competències genèriques abordades en el pregrau. Per a mesurar la dimensió cognitiva, es van dissenyar quatre preguntes de desenvolupament per identificar els coneixements sobre el concepte de cadascuna de les competències i es va construir una rúbricaper a avaluar l'acompliment dels estudiants en la dimensió conceptual. Tot i que la cognició no es troba solament referida a la part conceptual de la competència sinó també a les habilitats que es despleguen en el procés de coneixement, i fins i tot podria incloure la dimensió gestual que es relaciona amb el pensament, en aquest estudi es construeixen instruments que mesuren el que l'estudiant sap de cada competència i la complexitat en l'elaboració de les seues respostes.

Perquè els estudiants aplicaren les seues capacitats en relació a cada competència i per tant, mesurar la dimensió conductual, es va dissenyar una situació problema a la qual els estudiants havien de donar resposta individualment $\mathrm{i}$ per escrit a un cas al voltant de l'estat d'un aiguamoll i a la disputa generada entre els diversos actors involucrats -comunitat, polítics, ambientalistes, immobiliària-. Se'ls sol-licita que identifiquen un problema a partir del descrit en el cas, que avaluen, que oferisquen una solució i que analitzen conseqüències d'implementar-la. Posteriorment, se'ls demana que aborden la mateixa situació en grups de treball de cinc estudiants designats, mentre un avaluador observa el funcionament. Per mesurar l'acompliment dels estudiants davanttots dos escenaris es va construir una rúbrica analítica.

Finalment, per mesurarel desenvolupament de la dimensió afectiva dels estudiants, es va construir una escala de valoració en la qual manifesten la seua percepció sobre la importància que té desenvolupar aspectes relacionats amb les competències genèriques per al seu futur acompliment professional.

\section{Construcció $i$ anàlisi de les rúbriques i escala de valoració}

Considerant que els instruments i els reactius han de respondre a les prioritats institucionals i ser coherents amb la pedagogia proposada per la institució educativa (Reyes-Piñuelas, Luna-Serrano i Caso-Niebla, 2014), es va realitzar una anàlisi del que va declararla institució en el seu pla estratègic (Universitat de Concepción, 2015) i en el model de formació en competències genèriques(Navarro i al., 2015). De l'anàlisi i de la discussió d'experts, es van extraure nuclis conceptuals, aspectes afectius i conductuals, que van ser con- 
siderats com a essencials de cada competència genèrica en pensar en el perfil deltitulat de laUniversitat de Concepción, independent de la carrera d'estudi. Es constitueixen així com les unitats fonamentals de cada instrument. Una vegada construïts els instruments, es van sotmetre a una primera validació de jutges, que d'acord amb el que van assenyalar De Kelele i Gerard (2005 en Fernández, 2010) van verificar que els aspectes avaluats foren pertinents en funció dels paràmetres definits; a partir d'aquella discussió teòrica, es van fer les últimes modificacions dels instruments i una vegada que es va disposarde la seua aprovació, es va procedir a realitzar una aplicació pilot del sistema d'avaluació.

L'aplicació pilot es va dur a termea l'inici de l'any acadèmic 2015, amb 109 estudiants de primer any de la universitat -d'ells, 28,4\% homes i 71,6\% dones; pertanyents a tres carreres diferents: $18,3 \%$ d'educació general bàsica; 26,6\% d'Enginyeria Comercial i 55,0\% de Nutrició i Dietètica-. Una vegada obtingudes les dades, es va optar per analitzarla validesa de constructeutilitzant unaanàlisi factorial exploratòria(Campo-Arias i al., 2006; Marín-García i al., 2012) i anàlisi de la consistència interna de l'instrument, per mitjà del càlcul de l'Alpha de Chronbach (Anguiano i Velasco, 2012; Jonsson i Svingby, 2007; MacLaughlin, Fike, Alvarez, Seifert i Blaszczyk, 2010).El procediment de l'anàlisi factorial efectuat és el mateix que es descriu més endavant per a l'instrument final, per la qual cosa no s'aprofundirà en el procés en aquest apartat; no obstant això, s'esmenten alguns resultats generals obtinguts.

En relació a la dimensió cognitiva, es van extraure 4 factors amb autovalors $>1(3.424 ; 1.667 ; 1.375 ; 1.154)$, estructura coherent amb les dades obtingudes en realitzar l'anàlisi paral·lela sobre la base de 2000 mostres aleatòries. Per a la dimensió conductual, es van extraure quatre factors amb autovalors $>1$ $(3.940 ; 3.3034 ; 1.913 ; 1.101)$, no obstant això, l'anàlisi paral-lela sobre la base de 2000 mostres va indicar una estructura trifactorial, que va ser consistent amb l'estructura final de l'instrument.L'alfa de Cronbach calculat va ser 0.743. Finalment, el comportament de l'instrument per a avaluar la dimensió afectiva va ser similar al de la dimensió conductual. Es van extreure set factors amb autovalors $>1(5.464 ; 2.357 ; 1.423 ; 1.385 ; 1.201 ; 1.152 ; 1.065)$, no obstant això, l'anàlisi paral-lela sobre la base de 2000 mostres va indicar una estructura bifactorial amb pertinència significativa de tots els ítems. L'estructura bifactorial va ser consistent amb la de l'instrument final, no obstant això, va haver-hi variació en la pertinència total dels ítems en l'instrument final. L'alfa de Cronbach calculat per a l'instrument pilot va ser 0.851 .

A partir dels resultats d'aquestes anàlisis psicomètriques i de la pertinència de les dades obtingudes, se'n van fer les modificacions corresponents, per donar pas a l'aplicació oficial de l'instrument, la qual es descriu a continuació. 


\section{Metodologia}

\section{Participants}

Es va utilitzar una mostra no probabilística de 493 estudiants de primer any, corresponents al 10\% de la població total de 4891 estudiants ingressats a la Universitat de Concepción a través de la prova de selecció universitària, durant l'any 2015. Els estudiants pertanyien a 11 carreres diferents -Auditoria; Biologia; Infermeria; Enginyeria Civil Industrial; Enginyeria Civil Metal·lúrgica; Enginyeria Comercial; Odontologia; Pedagogia en Ciències Naturals i Biologia; Pedagogia en Ciències Naturals i Física; Pedagogia en Ciències Naturals i Química; Traducció i Interpretació d'Idiomes Estrangers-, les quals per a aquesta investigaciói com es mostra en la taula 2, van ser agrupades en tres àrees del coneixement: Física-Matemàtica, Química-Biològica, Social-Humanista.

TAULA 2

Carreres avaluades distribü̈des segons àrea del coneixement

\begin{tabular}{|l|l|l|}
\hline Física-Matemàtica & Química-Biològica & Social-Humanista \\
\hline Auditoria & Biologia & Enginyeria Comercial \\
Enginyeria Civil Industrial & Infermeria & Pedagogia en C. Naturals i Biologia \\
Enginyeria Civil & Odontologia & Pedagogia en C. Naturals i Física \\
Metal-lúrgica & & Pedagogia en C. Naturals i Química \\
& & Traducció i Interpretació d'Idiomes \\
& & Estrangers \\
\hline
\end{tabular}

En la taula 3 està la distribució mostral, la qual cerca respondre a dos criteris. En primer lloc, al criteri d'heterogeneïtat de la població,suggerit per Morales (2011) per a realitzar una anàlisi factorial efectiva. En relació al criteri anterior, el percentatge d'estudiants ingressats a la Universitat de Concepción durant l'any 2015, es distribueix de la manerasegüent: $30 \%$ ingressa a carreres de l'àrea Física-Matemàtica, 31\% a carreres de l'àrea Química-Biològicai 39\% a carreres de l'àrea Social-Humanista. En comparar aquestes dades amb les descrites en la taula 3 , és possible observar que la distribució de la mostra no es comporte de la mateixa manera que la distribució poblacional. No obstant això, sí compleix el criteri d'heterogeneïtat i es considera adequada per a realitzar l'anàlisi factorial.

El segon criteri, correspon a la grandària de la mostra. D'acord amb el que suggereix Beavers $i$ al. (2013), per a realitzar anàlisi factorial d'instrumentsquan els factors són definits per poques variables i tenen baixa càrrega, se suggereix una mostra d'almenys 300 individus. L'anàlisi del'aplicació pilot 
va mostrar una estructura factorial amb càrregues baixes a moderades i poques variables per factor, per la qual cosa es va confirmar la decisió de treballar amb una mostra de 493 individus.

TAULA 3

Distribució mostral

\begin{tabular}{|l|c|c|c|c|}
\hline \multicolumn{5}{|c|}{ ÀREA } \\
\hline & Física-Matemàtica & Química-Biològica & Social-Humanista & Total \\
\hline Dona & $12.17 \%$ & $28.60 \%$ & $11.36 \%$ & $52.13 \%$ \\
Tome & $23.94 \%$ & $14.40 \%$ & $9.53 \%$ & $47.87 \%$ \\
Total & $36.11 \%$ & $43.00 \%$ & $20.89 \%$ & $100 \%$ \\
\hline
\end{tabular}

\section{Procediment}

Per realitzar l'anàlisi de la validesa i confiabilitat dels instruments es va utilitzar el paquet estadístic IBM SPSS Statistics 21. L'anàlisi psicomètrica dels instruments va implicar dues etapes: 1) Estructura factorial dels instruments, per mitjà d'una anàlisi factorial exploratòria (AFE) amb mètode d'extracció Màxima Versemblança i rotació obliqua, mètode suggerit quan es presumeix l'existència de factors subjacents als reactius observats i factors que podrien estar relacionats, cosa que sol succeir en ciències socials (Beavers i al., 2013); 2) Avaluació de consistència interna dels instruments, per mitjà del càlcul del coeficient de confiabilitat alfa de Cronbach.

\section{Resultats}

\section{Instrument dimensió cognitiva}

El càlcul de la mesura d'adequació mostra de Kaiser-Meyer-Olkin (KMO) va llançar un valor de 0.700 i la prova d'esfericitat de Bartlett va donar com a resultat $X^{2}=862.043 ; p<.000$, i es van complir les condicions per a realitzar una anàlisi factorial exploratòria. D'acord amb la regla de Kaiser-Guttman, se'n va extraure 5 factors amb autovalors $>1(2.746 ; 1.680 ; 1.448 ; 1.345 ; 1.005)$. Aquesta solució va llançar un ítem amb valor inferior a 0.30 (ítem cg_tee4; 0.268 ), valor que és considerat com a adequat per a establir la pertinència significativa d'un ítem a un factor determinat, per la qual cosa es va procedir a eliminar (Hair, Black, Babin, Anderson, i Tatham, 2005; Beavers i al., 2013). Una vegada realitzada l'eliminació, el valor de KMO va ser 0.690 i de la prova de Barlett $X^{2}=811.298 ; p<.000$, i es va mostrar novament l'evidència d'una anàlisi 
factorial (Beavers i al., 2013). Aquesta última va mostrar una nova estructura factorial, composta per una solució de quatre factors amb autovalors >1 . (2.746; $1.680 ; 1.448 ; 1.345)$.

Per complementar la decisió d'extracció de factors, primer es va efectuar el Scree Test de Cattell (Beavers i al., 2013; Costello i Osborne, 2005; Morales, 2011), el qual va mostrar la clara existència de quatre factors i a més es va realitzar una anàlisi paral·lela (Horn, 1965) sobre la base de 2000 mostres aleatòries, el qual va identificar quatre factors amb autovalors majors $(2.746 ; 1.680 ; 1.448$; 1.3448) als obtinguts en el percentil 95 de la simulació amb valors aleatoris $(1.316 ; 1.245 ; 1.192 ; 1.145)$, i va donar suport així a l'estructura tetrafactorial.

Finalment, com s'observa en la taula 4, l'instrument va quedar compost per quatre factors estructurats de la següent forma: factor 1 «Comprensió dels aspectes conceptuals de l'emprenedoria i treball en equip interdisciplinari», factor 2 «Comprensió dels aspectes conceptuals del Pensament Crític», factor 3 «Comprensió dels aspectes conceptuals de la Comunicació» i factor 4 «Comprensió dels aspectes conceptuals de la Responsabilitat Social».

TAULA 4

Matriu de configuració amb anàlisi factorial exploratòria i rotació Promax per a la rúbrica d'avaluació de dimensió cognitiva, solució de quatre factors*

\begin{tabular}{|l|c|c|c|c|}
\hline & Factor 1 & Factor 2 & Factor 3 & Factor 4 \\
\hline $\begin{array}{l}\text { Avaluació i millora del pensamentpropi } \\
\text { (cg_pc1) }\end{array}$ & 0.135 & $\mathbf{0 . 6 1 3}$ & 0.223 & 0.160 \\
Processos cognitius implicats en el PC & & & & \\
$\quad$ (cg_pc2) & 0.104 & $\mathbf{0 . 6 3 7}$ & 0.107 & 0.069 \\
Integració d'informació provinent de diver- & & & & \\
ses fonts (cg_pc3) & 0.153 & $\mathbf{0 . 5 6 3}$ & 0.197 & 0.165 \\
Expressió de la informació (cg_c1) & 0.195 & 0.305 & $\mathbf{0 . 3 9 3}$ & 0.202 \\
Comprensió de la informació (cg_c2) & 0.136 & 0.199 & $\mathbf{0 . 6 0 4}$ & 0.120 \\
Consideració d'altres (cg_c3) & 0.033 & 0.081 & $\mathbf{0 . 5 9 4}$ & 0.042 \\
Adequació del llenguatge utilitzat a la & & & & \\
$\quad$ situació comunicativa (cg_c4) & 0.168 & 0.146 & $\mathbf{0 . 4 1 8}$ & 0.156 \\
Interdependència entre les persones (cg_rs1) & 0.122 & 0.088 & 0.046 & $\mathbf{0 . 5 0 0}$ \\
Conciliació de necessitats (cg_rs2) & 0.218 & 0.099 & 0.157 & $\mathbf{0 . 6 8 1}$ \\
Intenció del comportament (cg_rs3) & 0.332 & 0.230 & 0.138 & $\mathbf{0 . 4 5 6}$ \\
Actitud emprenedora (cg_tee1) & $\mathbf{0 . 3 3 7}$ & 0.103 & 0.124 & 0.130 \\
Treball col-laboratiu i interdependent & & & & \\
$\quad$ (cg_tee2) & $\mathbf{0 . 5 9 3}$ & 0.082 & 0.157 & 0.227 \\
Treball interdisciplinari (cg_tee3) & $\mathbf{0 . 5 7 3}$ & 0.223 & 0.206 & 0.360 \\
Orientació social (cg_tee4) & 0.288 & 0.152 & 0.217 & 0.094 \\
Integració conceptual (cg_tee5) & $\mathbf{0 . 6 3 0}$ & 0.080 & -0.030 & 0.120 \\
\hline
\end{tabular}

* En negreta les càrregues factorials superiors a 0.30 . 
En relació a l'ítem cg_tee4, la primera solució va suggerir eliminar-lo, no obstant això, a causa de la seua pertinència teòrica i de les finalitats pedagògiques d'aquest instrument, es va prendre la decisió de mantenir-lo en la versió final. Del càlcul de la consistència interna de l'instrument es va obtenir un $\alpha$ de Cronbach de 0.663 , valor que resulta adequat per a les finalitats d'aquest instrument.

\section{Instrument dimensió conductual}

L'avaluació de pertinència de l'anàlisi factorial va llançar un valor KMO de 0.813 i $X^{2}=1526.175 ; p<.000$ en la prova de Barlett; i es complienaixí les condicions necessàries per a realitzar-lo. D'acord amb la regla de Kaiser-Guttman, se'n va extraure quatre factors amb autovalors $>1$ (3.859; 3.293; 1.674; 1.066) en la qual tots els ítems van tenir una pertinència significativa a un factor, mentre que el Scree Test de Cattell va mostrar una solució de tres factors clarament, però unquart que es va prestar a interpretació. Per determinar la solució factorial final, es va fer una anàlisi paral·lela sobre la base de 2000 mostres aleatòries i es va identificar tres factors amb autovalors majors $(3.859 ; 3.293 ; 1.674)$ als obtinguts en el percentil als obtinguts en el percentil 95 de la simulació amb valors aleatoris $(1.530 ; 1.409 ; 1.328)$, i es va suggerir una estructura trifactorial.

A partir de l'anàlisi psicomètrica, de l'objectiu de la construcció de l'instrument i del constructe teòric es va determinar l'estructura trifactorial il-lustrada en la taula 5. Els factors van quedar estructurats de la formasegüent: Factor 1 «Emprendre en equips de treball interdisciplinaris», factor 2 «Avaluació i conciliació de necessitats per a generar solucions sostenibles» i factor 3 «Millorament d'idees a partir de la comprensió i expressió verbal adequada al context».

L'alfa de Cronbach calculada va ser 0.777, valor que es considera molt adequat per a aquestes finalitats (Bojórquez i al., 2013; MacLaughlin i al., 2010). Atès que l'estructura factorial obtinguda no va ser la suposada, es va dur a terme una anàlisi de la consistència interna per a cada factor, i es va mostrar una correlació adequada entre els ítems de cadascun dels tres; els valors de l'alfa de Cronbach obtinguts per a cadascun són $0.870 ; 0.740$ i 0.708 , respectivament. 
TAULA 5

Matriu de configuració amb anàlisi factorial exploratòria i rotació Promax per a la rúbrica d'avaluació de dimensió conductual, solució de tres factors*

\begin{tabular}{|l|c|c|c|}
\hline & Factor 1 & Factor 2 & Factor 3 \\
\hline Integració d'informació provinent de diferents fonts & & & \\
(cd_pc1) & 0.063 & $\mathbf{0 . 6 3 1}$ & -0.008 \\
Avaluació de les idees pròpies (cd_pc2) & 0.066 & $\mathbf{0 . 4 7 3}$ & 0.216 \\
Millorament de les ideespròpies (cd_pc3) & -0.052 & 0.191 & $\mathbf{0 . 5 0 0}$ \\
Claredat en l'expressió (cd_c1) & -0.037 & 0.116 & $\mathbf{0 . 6 0 4}$ \\
Bona ortografia (cd_c2) & 0.017 & -0.015 & $\mathbf{0 . 3 0 8}$ \\
Adequació al context (cd_c3) & 0.001 & -0.074 & $\mathbf{0 . 6 3 4}$ \\
Compressió del missatge (cd_c4) & 0.023 & -0.121 & $\mathbf{0 . 9 2 4}$ \\
Conciliació de necessitats (cd_rs1) & -0.009 & $\mathbf{0 . 7 3 2}$ & -0.013 \\
Intenció del comportament (cd_rs2) & -0.014 & $\mathbf{0 . 6 0 0}$ & 0.010 \\
Sostenibilitat de la solució (cd_rs3) & -0.040 & $\mathbf{0 . 6 1 5}$ & -0.114 \\
Interdependència (cd_rs4) & -0.005 & $\mathbf{0 . 5 8 4}$ & 0.004 \\
Consideració d'altres en el treball (cd_tee1) & $\mathbf{0 . 7 9 2}$ & 0.020 & 0.007 \\
Lideratge compartit (cd_tee2) & $\mathbf{0 . 8 3 6}$ & -0.027 & -0.032 \\
Iniciativa en la superació d'obstacles (cd_tee3) & $\mathbf{0 . 8 2 0}$ & -0.004 & 0.015 \\
Interdisciplinarietat (cd_tee4) & $\mathbf{0 . 6 0 6}$ & 0.073 & -0.033 \\
Interdependència entre membres de l'equip (cd_tee5) & $\mathbf{0 . 7 6 5}$ & -0.040 & 0.030 \\
\hline
\end{tabular}

* En negreta les càrregues factorials superiors a 0.30.

\section{Instrument dimensió afectiva}

L'avaluació de pertinència de l'anàlisi factorial va llançar un valor KMO de 0.829 i $X^{2}=1533.256 ; p<.000$ en la prova d'esfericitat de Barlett, i es van complir així les condicions per a realitzar-la. D'acord amb la regla de KaiserGutmaan, se'n va extraure 5 factors amb autovalors majors d'1 (4.306; 1.394; $1.258 ; 1.127 ; 1.084)$. Aquesta solució factorial va produir 3 ítems amb valors sota 0.3 (af_pc1, af_pc2, af_tee2), els quals van ser eliminats perquè no complienel criteri de pertinència significativa (Beavers i al., 2013; Hair i al., 2005). Aquest procés esva realitzar cinc vegades fins a obtenir una solució bifactorial consistent, en la qual tots els ítems tingueren una pertinència significativa a un dels dos factors. En les cinc reduccions es van obtenir indicadors que van donar suport a la pertinència de l'anàlisi factorial.Per sustentar la decisió d'una estructura bifactorial, es va realitzar una anàlisi paral-lela sobre la base de 2000 mostres aleatòries i es van identificar dos factors amb autovalors majors (4.306; 1.394) als obtinguts en el percentil 95 de la simulació amb valors aleatoris $(1.421 ; 1.335)$, i es va suggerirla mateixa estructura bifactorial. En la taula 6, hi ha l'estructura que va resultar en extraure dos factors i eliminar aquellsítems 
amb valors menors a 0.3 , i va quedar composta així: factor 1 ; «Conèixer-me, conèixer els altres, integrar posicions i expressar-ho adequadament», compost pels ítems Af_pc3; Af_pc4; Af_c2; Af_c3; Af_c4; Af_rs2; Af_tee3: i el factor 2; «Exercir la professió pel bé comú», compost pels ítems Af_rs3; Af_rs4; Af_rs5.

TAULA 6

Matriu de configuració amb anàlisi factorial exploratòria i rotació Promax per a la rúbrica d'avaluació de dimensió afectiva, solució de dos factors*

\begin{tabular}{|l|c|c|}
\hline & Factor 1 & Factor 2 \\
\hline $\begin{array}{l}\text { Avaluar la meua forma de pensar sobre les coses (af_pc3) } \\
\text { Contrastar les meues idees amb les idees d'altres i les aportacions } \\
\text { provinents d'altres fonts, per generar una resposta més completa } \\
\text { (af_pc4) }\end{array}$ & $\mathbf{0 . 4 5 7}$ & 0.111 \\
$\begin{array}{l}\text { Escoltar amb respecte, atenció i empatia les opinions o idees } \\
\text { d'altres (af_c2) }\end{array}$ & $\mathbf{0 . 6 8 1}$ & -0.090 \\
$\begin{array}{l}\text { Manejar eficaçment elements de la comunicació verbal i no verbal } \\
\text { per poder expressar-me i comprendre d'altres de la millor manera } \\
\text { possible (af_c3) }\end{array}$ & $\mathbf{0 . 3 8 0}$ & 0.056 \\
$\begin{array}{c}\text { Exposar les meues idees i conviccions clarament i sense agredir } \\
\text { els altres (af_c4) }\end{array}$ & $\mathbf{0 . 4 8 9}$ & 0.204 \\
$\begin{array}{c}\text { Tenir com a eix, en la meua actuació professional, valors que } \\
\text { aporten a la justícia, equitat i dignitat de la persona (af_rs2) }\end{array}$ & $\mathbf{0 . 3 9 5}$ & 0.273 \\
$\begin{array}{c}\text { Conciliar la satisfacció de les meues necessitats personals amb la } \\
\text { satisfacció de les necessitats dels altres (af_rs3) }\end{array}$ & 0.217 & $\mathbf{0 . 3 1 6}$ \\
$\begin{array}{c}\text { Tenir en compte les conseqüències dels meus actes professionals } \\
\text { en el curt, mitjà i llarg termini (af_rs4) }\end{array}$ & 0.099 & $\mathbf{0 . 6 2 2}$ \\
$\begin{array}{c}\text { Exercir el meu rol professional de forma responsable per aportar } \\
\text { a la societat i al meu desenvolupament personal (af_rs5) } \\
\text { Considerar l'aportació d'altres àrees del coneixement en el moment } \\
\text { d'abordar un problema (af_tee3) }\end{array}$ & -0.193 & $\mathbf{0 . 9 3 0}$ \\
\hline
\end{tabular}

*En negreta les càrregues factorials superiors a 0.30 .

L'anàlisi de confiabilitat de l'instrument va llançar un alfa de Cronbach de 0.758 . Considerant que l'estructura factorial va ser diferent de l'esperada, es va dur a terme una anàlisi de la consistència interna per cada factor, i es va mostrar una correlació adequada entre els ítems de cadascun d'aquests, el valor de l'alfa de Cronbach obtingut per al factor 1 va ser 0.613 i per al factor 2, 0.703 . 


\section{Discussió}

El sistema d'avaluació proposat mesura les dimensions cognitiva, afectiva i conductual de quatre competències genèriques: pensament crític, comunicació, emprenedoria i treball en equip interdisciplinari i responsabilitat social, per mitjà de dues rúbriques analítiques i una escala de valoració. Les anàlisis psicomètriques realitzades als instruments van mostrar que la rúbrica construïda per a avaluar ladimensió cognitiva, es compon per una estructura tetrafactorial consistent amb els constructes teòrics que mesura, és a dir, la conceptualització de cadascuna de les competència genèriques. A més, presenta un nivell de consistència interna adequat, el qual permet suggerir l'ús d'aquest instrument per a l'avaluació d'aquesta dimensió en les competències. És important destacar que el valor de la prova d'adequació mostral KMO per a aquest instrument va ser 0.690, valor que d'acord amb Beavers i al. (2013) és considerat «mediocre» per afer anàlisi factorial, a causa de la baixa mesura de la variància compartida dels ítems. La revisió de literatura especialitzada realitzada per Izquierdo, Olea i Abad (2014) sobre anàlisi factorial exploratòria, en 117 estudis publicats entre el 2011 i 2012, indiquen que el rang del KMO utilitzat per a determinar la pertinència de l'anàlisi factorial varia entre 0.60 i 0.98 . D'acord amb l'anterior, es va decidir prosseguir amb l'anàlisi factorial, i se'n van obtenir els resultats descrits.

En relació a la dimensió conductual i a la rúbrica construïda per avaluar-la, es va obtenir una estructura trifactorial consistent, no obstant això, diferent de la de quatre factors que se suposava. Aquest aspecte podria relacionar-se amb el fet que la dimensió conductual de les competències genèriques suposa la integració de diferents competències, per tant, no podrien aïllar-se en observar-les, sinó que se suggereix fer un perfil d'eixida d'estudis que incloga tots els aspectes esperats en l'acompliment (Chapman i O'Neill, 2010). En el cas d'aquest instrument d'avaluació, hi ha tres constructes a la base de la dimensió conductual de les competències genèriques: emprendre en equips de treball interdisciplinaris, avaluació i conciliació de necessitats per a generar solucions sostenibles, i millorament d'idees a partir de la comprensió i expressió verbal adequada al context; tanmateix, cada criteri -reflectit en cada ítem de la rúbrica-, seguiria pertanyent significativament a un dels tres constructes, i per tant, el resultat obtingut a partir d'una avaluació amb aquest instrument, continuarà mesurant un perfil professional d'eixida d'estudis que inclou tots els aspectes que es consideren importants de cadascuna de les quatre competències genèriques.

Finalment, en relació a l'instrument per a avaluar la dimensió afectiva, es va obtenir una estructura composta per dos factors: conèixer-me, conèixer els altres, integrar posicions i expressar-ho adequadament i exercir la professió pel bé comú, amb un nivell adequat de consistència interna entre factors i de l'instrument en general. Tot i queaquests nivells són adequats, se suggereix que l'ins- 
trument s'utilitze amb precaució, ja que l'anàlisi mostra que l'instrument mesura la dimensió afectiva dels dos factors esmentats i no el valor lliurat a cadascuna de les competències genèriques per separat. Com s'observa, apareixen dos elements clarament, l'orientació de l'acompliment professional al valor del bé comú i els elements relacionats amb el pensament crític, comunicació $i$ treball en equip interdisciplinari, considerats importants per al futur acompliment professional. Se suggereix fer estudis addicionals que aprofundisquen en aquest aspecte.

Les anàlisis difoses en aquest document suggereixen que el sistema d'avaluació és apropiat per a mesurar el que els estudiants coneixen, les seues actituds i conductes en relació a les competències genèriques, la qual cosa es considera una aportació important a aquesta àrea del coneixement.

La formació transversal dels estudiants i en particular, la formació de competències genèriques, sembla posicionar-se amb més força dia a dia en les institucions d'educació superior, de tal forma que l'absència d'instruments vàlids i confiables que permeten avaluar-les i per tant, prendre decisions per al seu desenvolupament, es fa més potent. El sistema que es proposa espera ser una resposta a aquesta necessitat, ja que permet avaluar les tres dimensions de les competències genèriques a partir de respostes que lliuren els estudiants davant preguntes relacionades amb casos problemes. El sistema proposat és complex i requereix capacitació en el seu ús, no obstant això, es considera que si es fa adequadament, permetrà conèixer el perfil d'estudiants que ingressen en la institució d'educació superior respecte a les competències genèriques, aspectes que fins al moment no solen ser descrits en les universitats xilenes. I d'altra banda, permetrà realitzar un mesurament de l'assoliment dels resultats d'aprenentatge esperats en els diferents cicles de les carreres universitàries, per tant, la presa de decisions a escala de carrera o enl'àmbit institucional, que permeten promoure efectivament la formació transversal en els estudiants.

\section{Referències}

Anguiano, M. i Velasco, V. (2012). La construcción y evidencias de validez de una rúbrica analítica para la evaluación de ensayos. Revista de evaluación educativa, 1(2).

Beavers, A.; Lounsbury, J.; Richards, J.; Huck, S.; Skolits, G. i Esquivel, S. (2013). Practical considerations for using exploratory factor analysis in educational research. Practical Assessment, Research \& Evaluation, 18(6).

Bojórquez, J.; López, L.; Hernández, M. i Jiménez, E. (2013). Utilización del alfa de Cronbach para validar la confiabilidad de un instrumento de medición de satisfacción del estudiante en el uso del software Minitab. Innovation in Engineering, Technology and Education for Competitiveness and Prosperity (pp. 1-9). Cancún: LACCEI. 
Brewerton, M. (2004). Reframing the essential skills: implications of the $O E C D$. Obtingut de Ministry of Education of New Zeland: <http://www. tki.org.nz/r/nzcurriculum/whats_happening_e.php>.

Campo-Arias, A.; Díaz-Martínez, L.; Rueda-Jaimes, G.; Martínez-Mantilla, J.; Amaya-Naranjo, W. i Campillo, H. (2006). Consistencia interna y análisis factorial del cuestionarioscoff para tamizaje de trastorno de conducta alimentaria en adolescentes estudiantes: una comparación por género. Universitas Psychologica, 5(2), pp. 295-304.

Chapman, E. i O'Neill, M. (2010). Defining and assessing generic competencies in Australian universities: ongoing challenges. Education Research and Perspectives, 37(1), pp. 105-125.

Ciudad, A. i Valverde, J. (2014). Reliability analysis of an evaluation rubric for university accounting students: a learning activity about database use. Journal of International Education Research, 10(5), pp. 301-306.

Community research and development information service (2006). The Lisbon strategy for growth and jobs. Obtingut de <http://cordis.europa.eu/ programme/rcn/843_en.html>.

Costello, A. i Osborne, J. (2005). Best practices in exploratory factor analysis: four recommendations for getting the most from your analysis. Practical Assessment, Research \& Evaluation, 10(7).

Fernández, A. (2010). La evaluación orientada al aprendizaje en un modelo de formación por competencias en la educación universitaria. Revista de Docencia Universitaria, 8(1), pp. 11-34.

González, J. i Wagenaar, R. (2006). Tuning educational structures in Europe. Bilbao: Tuning project.

Hair, J.; Black, W.; Babin, B.; Anderson, R. i Tatham, R. (2005). Análisis multivariante. Madrid: Prentice Hall.

Horn, J. (1965). A rationale and test for the number of factors in factor analysis. Psychometrika, 30, pp. 179-185.

Irles, M.; Ortells, J.; De la Calle, M. i De la Sen Fernández, M. (2011). La rúbrica de evaluación como herramienta de evaluación formativa y sumativa. IX Jornades de xarxes d'investigació en docència universitària: disseny de bones pràctiques docents en el context actual [Recurso electrónico]. Alacant: Universitat d'Alacant, Vicerectorat d'Estudis, Formació i Qualitat, Institut de Ciències de l'Educació (ICE).

Izquierdo, I.; Olea, J. i Abad, F. (2014). Exploratory factor analysis in validation studies: uses and recommendations. Psicothema, 26(3), pp. 395-400.

Jonsson, A. i Svingby, G. (2007). The use of scoring rubrics: reliability, validity and educational consequences. Educational Research Review, 2, pp. 130-144.

MacLaughlin, J.; Fike, D.; Alvarez, C.; Seifert, C. i Blaszczyk, A. (2010). Reliability of a seminar grading rubric in a grand rounds course. Journal of Multidisciplinary Healthcare Dovepress, 3, pp. 169-179. 
Marín-García, A.; Watts, F.; Fernández-March, A.; Aznar-Mas, L.; Pérez-Peñalver, M.; Montero-Fleta, B.; ... Orozco-Mesana, J. (2012). Validación de una rúbrica para la evaluación de la competencia de innovación en alumnos universitarios. Jornadas de Innovación Educativa de la UPV (pp. 180183). València: UPV Institut de Ciències de l'Educació.

Mashitoh, Y. (2012). Integrating generic competencies (GCs) into University's compulsory courses: perspectives of lecturers and students. Procedia, 59, pp. 574-583.

Morales, P. (8 de maig de 2015). El Análisis Factorial en la construcción e interpretación de tests, escalas y cuestionarios. Madrid: Universitat Pontificia Comillas; 2011. Obtingut de <http://www.upcomillas.es/personal/ peter/investigacion>.

Navarro, G.; Vaccarezza, G.; González, M. i Catalán, R. (2015). Construcción de conocimiento en educación superior: Educación de competencias genéricas en la Universidad de Concepción (Chile). (G. Navarro, Ed.) Concepción: Sello editorial Universitat de Concepción.

Navarro, I. i González, C. (2010). La autoevaluación y la evaluación entre iguales como estrategia para el desarrollo de competencias profesionales: Una experiencia docente en el grado de maestro. Revista de Docencia Universitaria, 8(1), pp. 187-200.

Neligia, B. (2001). Una técnica para la medición de actitudes sociales. Revista de Ciencias Sociales (RCS), 7(1), pp. 45-54.

Nordenflycht, M. (2011). Enseñanza y aprendizaje por competencias. Pensamiento Educativo: Revista de Investigación Educacional Latinoamericana, 36(1), pp. 80-104.

Qualifications and Curriculum Authority (2004). The key skills qualifications standards and guidance. Londres: QCA.

Raymond, J.; Homer, C.; Smith, R. i Gray, J. (2013). Learning through authentic assessment: An evaluation of a new development in the undergraduate midwifery curriculum. Nurse Education in Practice, 13, pp. 471-476.

Reyes-Piñuelas, E.; Luna-Serrano, E. i Caso-Niebla, J. (2014). Propiedades psicométricas del cuestionario de evaluación de la competencia docente. Revista Iberoamericana de Evaluación Educativa, 7(2), pp. 117-130.

Sabirón, F. i Arraiz, A. (2013). Aprendiendo de la evaluación: decálogo para la evaluación auténtica de competencias profesionales a través del portafolio. Revista Iberoamericana de Evaluación Educativa, 6(1), pp. 135-152.

Universitat de Concepción (5 de maig de 2015). Plan estratégico institucional 2011-2015. Obtingut de <http://www.udec.cl/intranet/documentos_ oficiales/PEI_2011_2015_web.pdf>.

Data de recepció: $\quad$ 08-04-2016

Data d'acceptació: 20-04-2016 